\title{
ais sencer
}

\section{Don't hedge(hog) your bets}

Medulloblastoma is the most commonly occurring malignant brain tumour in children. This cancer is associated with activation of specific signalling pathways, including sonic hedgehog (SHH). Although it had been established that germline mutations in the SUFU gene (part of the SHH signalling pathway) were linked to genetic predisposition to medulloblastoma, it was unclear if this gene had a role in sporadically occurring disease. Now, a study has shown that for certain patient subgroups, the SUFU gene has a likely role in carcinogenesis, and genetic tests should be routine for these patients to aid in treatment decisions.

This project was led by Laurence Brugières who explained the background of the work: "we decided to do this research project since we had previously identified a germline SUFU mutation in two families with several children under 3 diagnosed with desmoplastic/nodular medulloblastoma or medulloblastoma with extensive nodularity (MBEN). We could show that the penetrance of this mutation is incomplete and thus that this mutation could be transmitted by healthy parents to patients with apparently sporadic medulloblastoma." To investigate this observation further, Brugières and her team performed complete genetic analysis of the SUFU gene in 131 paediatric patients who were treated for medulloblastoma at Institut Gustave Roussey.

Germline mutations in the SUFU gene were found in eight patients with apparently sporadic cancer who were all under the age of 3 years at the time of diagnosis. The type of medulloblastoma was important; three of the patients with the mutations had MBEN (100\% of patients in the sample with this category of disease), four had desmoplastic/nodular medulloblastoma (20\%), and one had classic medulloblastoma (1\%). Brugières explained that "most of these mutations are inherited from a healthy parent." Indeed, in those patients whose parents agreed to undertake genetic testing, four patients with medulloblastoma had inherited the defective gene from their healthy father, and in two patients the mutations were de novo.

Based on these data, it would seem that in patients with desmoplastic/nodular medulloblastoma or MBEN who are diagnosed before the age of 3 , it is not possible to rule out inheritance of the illness even in cases where there is no

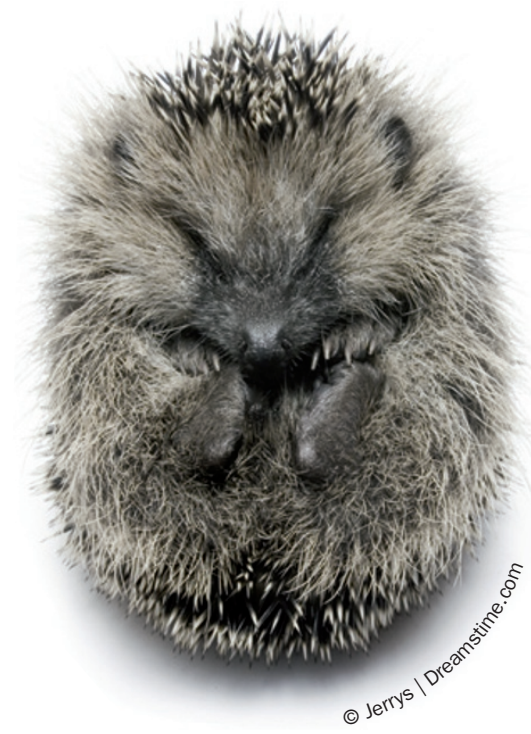

family history of the disease. Therefore, Brugières says "the main implication of this work is the necessity to offer genetic testing in young children affected by medulloblastoma." The results from this testing could allow genetic counselling for the families of the patients to enable the detection of siblings or other family members at high risk of cancer.

Rebecca Kirk

Original article Brugières, L. et al. High frequency of germline SUFU mutations in children with desmoplastic/ nodular medulloblastoma younger than 3 years of age. J. Clin. Oncol. doi:10.1200/JC0.2011.38.7258 